\title{
The effect of the difference in $\mathrm{C}_{2-7}$ angle on the occurrence of dysphagia after anterior cervical discectomy and fusion with the zero-P implant system
}

\author{
Cheng-Yi Huang ${ }^{1 \dagger}$, Yang Meng ${ }^{1 \dagger}$, Bei-Yu Wang ${ }^{1}$, Jie Yu², Chen Ding ${ }^{1}$, Yi Yang ${ }^{1}$, Ting-Kui Wu ${ }^{1}$ and Hao Liu ${ }^{1 *}$
}

\begin{abstract}
Objectives: To investigate the effect of the difference in $\mathrm{C}_{2-7}$ angle on dysphagia after anterior cervical discectomy and fusion (ACDF) with the Zero-P Implant System.

Methods: A retrospective analysis of 181 patients who underwent ACDF with the Zero-P Implant System and had at least one year of follow-up from January 2011 to November 2018 was performed. All patients were divided into a non-dysphagia group and a dysphagia group to explore the effect of the difference between postoperative and preoperative $\mathrm{C}_{2-7}$ angle $\left(\mathrm{dC}_{2-7} \mathrm{~A}\right)$ on postoperative dysphagia. At the same time, other possible related factors including the difference between postoperative and preoperative O-C2 angle (dO-C2A), sex, age, body mass index (BMI), intraoperative time, estimated blood loss, diabetes mellitus, hypertension, smoking, alcohol consumption, prevertebral soft-tissue swelling (PSTS), the highest segment involved in the surgery and the levels of surgery segments were analyzed.
\end{abstract}

Results: In total, the non-dysphagia group comprised 139 patients and the dysphagia group comprised 42 patients. The single-factor analysis showed that smoking, PSTS and $\mathrm{dC}_{2-7} \mathrm{~A}$ were significantly different between the two groups $(P<0.05)$. Spearman's correlation coefficient showed no significant correlation between the degree of dysphagia and $\mathrm{dC}_{2-7} \mathrm{~A}(P>0.05)$. The results of the multiple-factor analysis with an ordinal logistic regression model showed that smoking, PSTS and $d_{2-7} A$ were significantly associated with the incidence of dysphagia $(P<0.05)$.

Conclusions: The postoperative $\mathrm{C}_{2-7}$ angle has an important effect on the occurrence of dysphagia in patients undergoing Zero-P implant system interbody fusion surgery.

Keywords: Dysphagia, Zero-P, Cervical vertebrae, Related factors

\section{Introduction}

Anterior cervical discectomy and fusion (ACDF) has become a widely accepted and practiced surgical intervention for the treatment of cervical spondylosis and disc

\footnotetext{
* Correspondence: liuhaohxyy@163.com

${ }^{\dagger}$ Cheng-Yi Huang and Yang Meng contributed equally to this work.

'Department of Orthopedic Surgery, West China Hospital, Sichuan University, No. 37 Guo Xue Xiang, Chengdu 610041, Sichuan, China

Full list of author information is available at the end of the article
}

herniation [1, 2]. Traditional ACDF has been applied with an anterior titanium alloy plate in cervical spine surgery to maintain or increase the alignment and stability of the cervical sagitta, increase the fusion rate, and decrease the potential for graft extrusion and subsidence, particularly in surgery involving multiple segments [1-4]. Unfortunately, the utilization of the anterior plate significantly increases the risk of dysphagia after surgery, and this procedure is often complicated by the collapse of the grafted bone,

(c) The Author(s). 2020 Open Access This article is licensed under a Creative Commons Attribution 4.0 International License, which permits use, sharing, adaptation, distribution and reproduction in any medium or format, as long as you give appropriate credit to the original author(s) and the source, provide a link to the Creative Commons licence, and indicate if changes were made. The images or other third party material in this article are included in the article's Creative Commons licence, unless indicated otherwise in a credit line to the material. If material is not included in the article's Creative Commons licence and your intended use is not permitted by statutory regulation or exceeds the permitted use, you will need to obtain permission directly from the copyright holder. To view a copy of this licence, visit http://creativecommons.org/licenses/by/4.0/. The Creative Commons Public Domain Dedication waiver (http://creativecommons.org/publicdomain/zero/1.0/) applies to the data made available in this article, unless otherwise stated in a credit line to the data. 
pseudarthrosis, kyphotic deformity, and graft donor site morbidity [5-7]. To reduce the incidence of complications such as dysphagia, a new stand-alone zero-profile device (Zero-P, Synthes GmbH, Switzerland) is commonly used for ACDF in our hospital. Although the Zero-P Implant System has been confirmed to reduce the incidence of complications to a considerable degree, many patients suffer from dysphagia after surgery [8-10]. Some previous studies have conducted risk factor analyses of postoperative dysphagia after traditional ACDF $[1,5]$, but few studies have focused on the related factors of postoperative dysphagia in ACDF with the Zero-P Implant System.

We noticed that after the ACDF with Zero-P, the changes in lordosis in some patients were obvious, especially the $\mathrm{C} 2-7$ angle; these changes could cause changes in the anatomical relationship between the cervical spine and the anterior esophagus, which may cause dysphagia. Several retrospective studies have reported that the change in $\mathrm{O}-\mathrm{C}_{2} \mathrm{~A}$ plays an important role in the development of dysphagia after occipitocervical fusion [11, 12]. A retrospective study based on 392 patients showed that the change in $\mathrm{C}_{2-7}$ angle plays an important role in the development of dysphagia in both ACDF with anterior plate and posterior cervical laminoplasty [13]. However, few reports have described the effect of the difference between postoperative and preoperative $\mathrm{C}_{2-7}$ angle $\left(\mathrm{dC}_{2-7} \mathrm{~A}\right)$ on postoperative dysphagia after ACDF with Zero-P.

Thus, considering the paucity of clinical data in this field, a retrospective analysis of patients who underwent ACDF with the Zero-P Implant System was performed in our center to investigate the effect of the $\mathrm{dC}_{2-7} \mathrm{~A}$ and other possible related factors on dysphagia. Practical references are provided for future surgeries to further reduce the incidence of dysphagia after ACDF with Zero-P.

\section{Materials and methods}

This retrospective study was approved by the Medical Ethics Committee of West China Hospital, Sichuan University, China. All of the patients were recruited after providing informed consent for analysis of their clinical data.

\section{Inclusion and exclusion criteria for patients Inclusion criteria}

(1) Patients with radiculopathy or myelopathy from single-level or multilevel cervical disc disease with correlating magnetic resonance imaging findings and no response to conservative treatment for more than 6 weeks; (2) patients aged over 18 years who underwent $\mathrm{ACDF}$ with the Zero-P Implant System from $\mathrm{C}_{3}$ to $\mathrm{C}_{7}$; (3) patients with detailed postoperative anteroposterior and lateral X-rays and clinical data; and(4) patients who had accepted at least one year of follow-up.

\section{Exclusion criteria}

(1) Patients with dysphagia before the surgery; (2)patients with psychological diseases such as mania and severe depression or a history of central nervous system disorders such as traumatic brain injury and brain stroke;(3) patients who had a history of esophageal disease, revision surgery and neck surgery; and (4) patients with pathologic fractures of the vertebrae, spinal deformity, ossification of the posterior longitudinal ligament (OPLL), rheumatoid arthritis, ankylosing spondylitis, developmental stenosis and local or systemic infections.

This retrospective review was conducted with 181 patients who underwent ACDF with the Zero-P Implant System between January 2011 and November 2018 in West China Hospital, Sichuan University, Sichuan, China. All patients were treated, nursed and followed up in the Department of Orthopedics, West China Hospital.

\section{Surgical technique}

All surgical procedures were performed by senior spinal surgeons in our department with a standard, right Smith-Robinson approach after the induction of general anesthesia [14, 15]. A transverse incision from the midline to the anterior border of the sternocleidomastoid was used to reach the perpendicularly spreading fibers of the platysma, and then the platysma was split longitudinally. Complete discectomy was performed at the index levels by removing the disc tissue, posterior longitudinal ligament and osteophytes to achieve thorough decompression. After the endplates were well prepared, a properly sized Zero-P implant filled with a composite synthetic bone graft (beta-tricalcium phosphate, $\beta$-TCP, ChronOS; DePuySynthes, Paoli, CA, USA) was implanted into the index levels. The locking head screws were screwed into place after final imaging of the device was performed. Layer-by-layer suturing and incision closure were performed after drainage insertion. All patients received methylprednisolone at a dosage of 100 mg per day during the 3 days after the surgery; meanwhile, rhBMP-2 was not used.

\section{Dysphagia evaluation}

The Bazaz grading system was chosen to evaluate dysphagia after surgery because it has been commonly used in previous studies [16]. The Bazaz grading system is a qualitative, unvalidated grading scale used to obtain patients' perception of their difficulty swallowing liquids and solids based on individualized information. The scores of the Bazaz grading system were ranked as follows: 0-none, 1-mild, 2-moderate and 3-severe, representing no episodes of swallowing problems, rare episodes of dysphagia, occasional swallowing difficulties with specific foods and frequent swallowing difficulties with most foods, respectively. In this study, the grade of 
dysphagia was evaluated by investigators via telephone interviews or outpatient follow-up visits based on the information provided by the patients, and the patients were promptly evaluated for dysphagia 1 week after surgery and at each follow-up point. Patients were divided into two groups according to the presence or absence of dysphagia (Table 1).

\section{Radiographic assessment}

PACS version 4.0 (GE Healthcare, Milwaukee, WI) was used for measuring the $\mathrm{O}-\mathrm{C} 2$ angle $\left(\mathrm{O}-\mathrm{C}_{2} \mathrm{~A}\right), \mathrm{C}_{2-7}$ angle $\left(\mathrm{C}_{2-7} \mathrm{~A}\right)$ and prevertebral soft-tissue thickness (PSTT). The angle between the inferior margin of the $C_{2}$ vertebrae and the inferior margin of the $C_{7}$ vertebrae was measured as the $\mathrm{C}_{2-7}$ angle $[17,18]$ while the angle between the McGregor's line and the inferior margin of the $\mathrm{C}_{2}$ vertebrae was measured as the $\mathrm{O}-\mathrm{C} 2$ angle perioperatively on plain lateral cervical radiographs [19]. The prevertebral soft tissue thickness was measured at the extended line of the anteroposterior (AP) diameter which ends at the posterior aspect of the trachea from $\mathrm{C}_{2}$ to $\mathrm{C}_{7}$, and the AP diameter was measured between the centers of the posterior and anterior cortex of each vertebral body (Fig. 1) [20]. The average of the PSTT from $\mathrm{C}_{2}$ to $\mathrm{C}_{7}$ was taken for analysis. The difference between the postoperative and preoperative $\mathrm{O}-\mathrm{C}_{2}$ angle $\left(\mathrm{dO}-\mathrm{C}_{2} \mathrm{~A}\right)$, the difference between the postoperative and preoperative $\mathrm{C}_{2-7}$ angle $\left(\mathrm{dC}_{2-7} \mathrm{~A}\right)$ and prevertebral softtissue swelling (PSTS) were calculated from the following formulas: $d O-C_{2} A=$ postoperative $O-C_{2} A-$ preoperative $\quad \mathrm{O}-\mathrm{C}_{2} \mathrm{~A}, \quad \mathrm{dC_{2-7 }} \mathrm{A}=$ postoperative $\quad \mathrm{C}_{2-7} \mathrm{~A}-$ preoperative $\mathrm{O}-\mathrm{C}_{2} \mathrm{~A}$, and $\mathrm{PSTS}=$ postoperative $\mathrm{PSTT}$ -preoperative PSTT. The measurement time of the Xrays was 1 week after surgery, and two independent radiologists performed the assessment of the X-rays

\section{Statistical analysis}

All statistical analyses were performed with the statistical program SPSS version 22.0 (SPSS Inc., Chicago, IL, USA). The investigators used descriptive statistics such as the means, standard deviations and ratio index to represent the quantitative and categorical variables. For the single-factor analysis, a chi-squared test and Student's ttest were conducted for enumeration and measurement data, respectively. Spearman's correlation coefficient was calculated between the degree of dysphagia and $\mathrm{dC}_{2-7} \mathrm{~A}$.

Table 1 The Bazaz grading system

\begin{tabular}{lll}
\hline Severity & Liquids & Solids \\
\hline 0-None & None & None \\
1-Mild & None & Rare \\
2-Moderate & None or rare & Occasionally \\
3-Severe & None or rare & Frequent \\
\hline
\end{tabular}

To eliminate the influence of confounding factors, ordinal logistic regression was performed for multifactor regression of factors with a $P$ value less than 0.2 in the singlefactor analysis. The results were regarded as significant when the $P$-values were less than 0.05 in this study.

\section{Results}

In total, 181 consecutive patients were enrolled in this study according to the inclusion and exclusion criteria listed above, including 104 males and 77 females with ages ranging from 25 to 77 years and an average age of $52.15 \pm$ 9.32 years. The dysphagia group consisted of 42 consecutive patients while the non-dysphagia group consisted of 139 consecutive patients. The difference in preoperative $\mathrm{C}_{2-7} \mathrm{~A}, \mathrm{O}-\mathrm{C}_{2} \mathrm{~A}$ and PSTT between the two groups was not significant $(P>0.05)$, whereas the postoperative $\mathrm{C}_{2-7} \mathrm{~A}$, $\mathrm{O}$ $\mathrm{C}_{2} \mathrm{~A}$ and PSTT were significantly different between the two groups $(P<0.05)$ (Table 2$)$. The mean follow-up period was 18 months (range: 12 to 24 months).

\section{Single-factor analysis between the postoperative $\mathrm{C}_{2-7}$ angle and dysphagia}

According to the assessment and statistical analysis of the radiographs, we evaluated the role of $\mathrm{dC}_{2-7} \mathrm{~A}$ in the development of dysphagia and found a significant difference in $\mathrm{dC}_{2-7}$ angle for dysphagia and non-dysphagia patients in the two groups. $(P<0.01$, Table 3$)$. Moreover, 63 of the 181 patients had a postoperative $\mathrm{dC}_{2-7} \mathrm{~A}<-1^{\circ}$, dysphagia occurred in 5 of those patients, and the incidence rate was $7.94 \%(5 / 63)$. Meanwhile, 118 of the 181 patients had a postoperative $\mathrm{dC} 2-7 \mathrm{~A} \geq-1^{\circ}$, dysphagia occurred in 37 of those patients, and the incidence rate was $31.36 \%(37 / 118)$. The difference was significant $(P<$ 0.05) (Fig. 2).

In the dysphagia group, 26 patients suffered from mild dysphagia, 9 patients suffered from moderate dysphagia, and 7 patients suffered from severe dysphagia according to the Bazaz grading system. Spearman's correlation coefficient of the dysphagia group between the degree of dysphagia and the incidence of postoperative dysphagia showed no significant correlation $(\mathrm{r}=0.051, P=0.747)$.

\section{Single-factor analysis between other related factors and dysphagia}

Table 3 shows that the distribution of age, sex and BMI was similar in the dysphagia and non-dysphagia groups $(P>0.05)$. The prevalence of diabetes mellitus and hypertension was not significantly different between the two groups $(P>0.05)$, and similar results were obtained for alcohol consumption $(P>0.05)$. However, smoking was significantly different between the two groups $(P<$ $0.05)$. The postoperative $\mathrm{O}-\mathrm{C}_{2}$ angle was similar $(\mathrm{P}>$ $0.05)$, whereas the PSTS in the two groups was significantly different $(\mathrm{P}<0.05)$. The intraoperative time and 

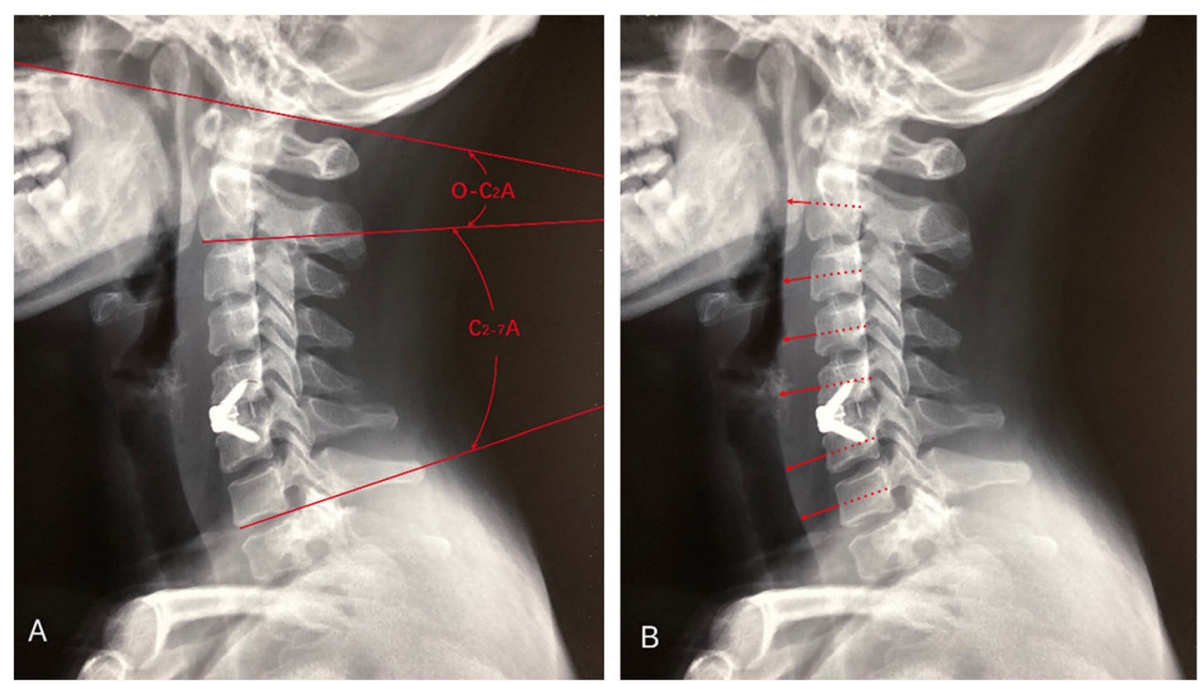

Fig. 1 The measurement of $\mathrm{O}-\mathrm{C}_{2} \mathrm{~A}, \mathrm{C}_{2-7} \mathrm{~A}(\mathbf{a})$ and PSTT(b) on postoperative lateral X-rays. The angle between the inferior margin of the $C_{2}$ vertebrae and the inferior margin of the $C_{7}$ vertebrae was measured as the $C_{2-7}$ angle while the angle between the McGregor's line and the inferior margin of the $C_{2}$ vertebrae was measured as the O-C2 angle perioperatively on plain lateral cervical radiographs (a). The PSTT was measured at the extended line of the AP diameter from $C_{2}$ to $C_{7}$, and the AP diameter was measured between the center of the posterior and anterior cortex of each vertebral body. O- $C_{2} A$ : O- $C_{2}$ angle, $C_{2-7} A: C_{2-7}$ angle, AP: Anteroposterior, PSTT: Prevertebral soft tissue thickness

estimated mean blood loss were not significantly different in the dysphagia and non-dysphagia groups $(P>$ 0.05). With regard to the highest segment involve in the surgery, the mean was found to be not significantly different between the dysphagia and non-dysphagia groups $(P>0.05)$. In addition, the single-level, two-level, and three-level surgeries were denoted by "1", "2" and "3", respectively, for the analysis of the levels of surgery, and the levels of both groups ranged from 1 to 3 . Between the average level in the dysphagia and non-dysphagia groups, no significant differences were observed $(P>0.05)$.

\section{Multivariate logistic regression analysis}

Ordinal logistic regression was performed for multifactor regression of the factors that had a $P$ value less than 0.2 in the single factor analysis, including age, BMI, smoking, estimated blood loss, PSTS and $\mathrm{dC}_{2-7} \mathrm{~A}$. The results showed that smoking, PSTS (Fig. 3) and $\mathrm{dC}_{2-7} \mathrm{~A}$ (Fig. 4) were significantly associated with a higher incidence of dysphagia $(P<0.05)$, whereas age, BMI and estimated blood loss were not associated with a higher incidence of dysphagia $(P>0.05)$. The results of the multiple factors analysis are shown in Table 4.

\section{Discussion}

Dysphagia, or swallowing dysfunction, can possibly reduce patient satisfaction with surgery, lead to various degrees of discomfort, and increase the risk of various complications such as bronchospasm, aspiration pneumonia, dehydration, asphyxia and malnutrition [21]. Dysphagia is a postoperative result triggered by multiple factors, and it is reported to be the most common early complication after ACDF [21-23]. Rihn et al. [24] concluded that dysphagia appeared among $70 \%$ of patients who underwent anterior cervical surgery. With a mean of 7.2 years of follow-up, Yue et al. [25] found varying degrees of dysphagia occurring after ACDF with an anterior cervical plate, with an incidence of $35.1 \%$ at the final follow-up.

Table 2 The pre- and postoperative radiographic parameters

\begin{tabular}{llll}
\hline Groups & Non-dysphagia group $(\boldsymbol{N = 1 3 9 )}$ & Dysphagia group $(\boldsymbol{N}=\mathbf{4 2})$ & $\boldsymbol{P}$ \\
\hline Preoperative $\mathrm{O}-\mathrm{C}_{2}$ angle $\left(^{\circ}\right)$ & $16.14 \pm 6.77$ & $15.36 \pm 6.56$ & 0.510 \\
Postoperative $\mathrm{O}-\mathrm{C}_{2}$ angle $\left(^{\circ}\right)$ & $15.78 \pm 3.60$ & $14.46 \pm 3.48$ & $\mathbf{0 . 0 3 7}$ \\
Preoperative $\mathrm{C}_{2-7}$ angle $\left(^{\circ}\right)$ & $15.02 \pm 11.61$ & $15.40 \pm 7.92$ & 0.843 \\
Postoperative $C_{2-7}$ angle $\left(^{\circ}\right)$ & $12.14 \pm 5.23$ & $19.77 \pm 6.17$ & $<\mathbf{0 . 0 0 1}$ \\
Preoperative PSTT $(\mathrm{mm})$ & $9.39 \pm 1.53$ & $11.65 \pm 1.88$ & 0.386 \\
Postoperative PSTT $(\mathrm{mm})$ & $14.91 \pm 4.06$ & $18.06 \pm 3.07$ & $<\mathbf{0 . 0 0 1}$ \\
\hline
\end{tabular}


Table 3 Comparison of factors of dysphagia after surgeries

\begin{tabular}{|c|c|c|c|}
\hline Groups & Non-dysphagia group $(N=139)$ & Dysphagia group $(N=42)$ & $P$ \\
\hline$\overline{\text { Sex }(\text { male/female) }}{ }^{\mathrm{b}}$ & $78 / 61$ & $26 / 16$ & 0.506 \\
\hline Age $(y)^{a}$ & $52.71 \pm 9.98$ & $50.31 \pm 6.41$ & 0.145 \\
\hline $\mathrm{BMI}^{\mathrm{a}}$ & $23.75 \pm 2.92$ & $24.67 \pm 3.29$ & 0.084 \\
\hline Diabetes mellitus (yes/none) ${ }^{b}$ & $5 / 134$ & $2 / 40$ & 0.732 \\
\hline Hypertension (yes/none) ${ }^{b}$ & $2 / 127$ & $5 / 37$ & 0.524 \\
\hline Smoking (yes/none) ${ }^{\mathrm{b}}$ & $31 / 108$ & $20 / 22$ & 0.001 \\
\hline Alcohol consumption (yes/none) ${ }^{b}$ & $45 / 94$ & $17 / 25$ & 0.332 \\
\hline Intraoperative time $(\mathrm{min})^{\mathrm{a}}$ & $147.60 \pm 17.23$ & $150.43 \pm 18.60$ & 0.361 \\
\hline Estimated blood loss $(\mathrm{ml})^{\mathrm{a}}$ & $80.72 \pm 78.73$ & $58.10 \pm 22.87$ & 0.068 \\
\hline Prevertebral soft-tissue swelling $(\mathrm{mm})^{a}$ & $5.52 \pm 0.67$ & $6.41 \pm 0.87$ & $<0.001$ \\
\hline $\mathrm{dO}-\mathrm{C}_{2} \mathrm{~A}\left({ }^{\circ}\right)^{\mathrm{a}}$ & $-0.37 \pm 7.68$ & $-0.91 \pm 7.22$ & 0.687 \\
\hline $\mathrm{dC}_{2-7} \mathrm{~A}\left({ }^{\circ}\right)^{\mathrm{a}}$ & $-2.88 \pm 9.69$ & $4.37 \pm 6.82$ & $<0.001$ \\
\hline The highest segment involved in the surgery ${ }^{a}$ & $6.15 \pm 0.79$ & $6.29 \pm 0.77$ & 0.332 \\
\hline Number of surgery segments ${ }^{a}$ & $1.91 \pm 0.76$ & $1.81 \pm 0.55$ & 0.444 \\
\hline
\end{tabular}

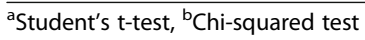

The mechanism underlying the occurrence of postoperative dysphagia is still controversial. Dysphagia is possibly associated with damage to the swallowing center in the central nervous system or cortical areas, dysfunction of efferent nerves or muscular drive or decreased pharyngolaryngeal sensitivity. Disorders of esophageal motility caused by intra-operative traction or mechanical stimulation during surgery have often been mentioned in previous studies [26]. Swelling of the soft tissue around the esophagus and anterior cervical plate after ACDF are also commonly recognized as causes of postoperative dysphagia [27, 28]. Attempts have been made in recent years to overcome the limitations of the traditional anterior plate. Lee et al. [29] proved that a low-

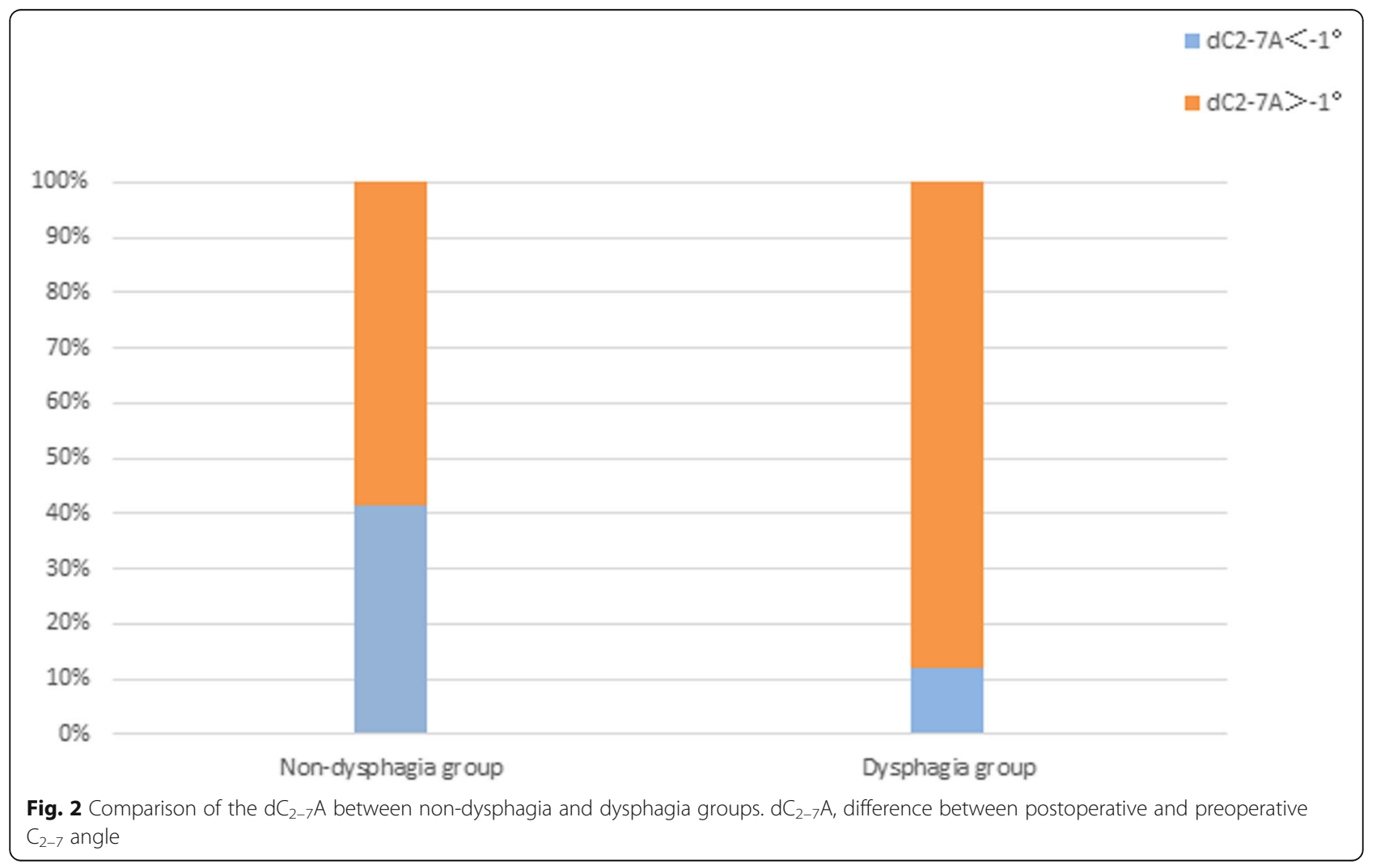



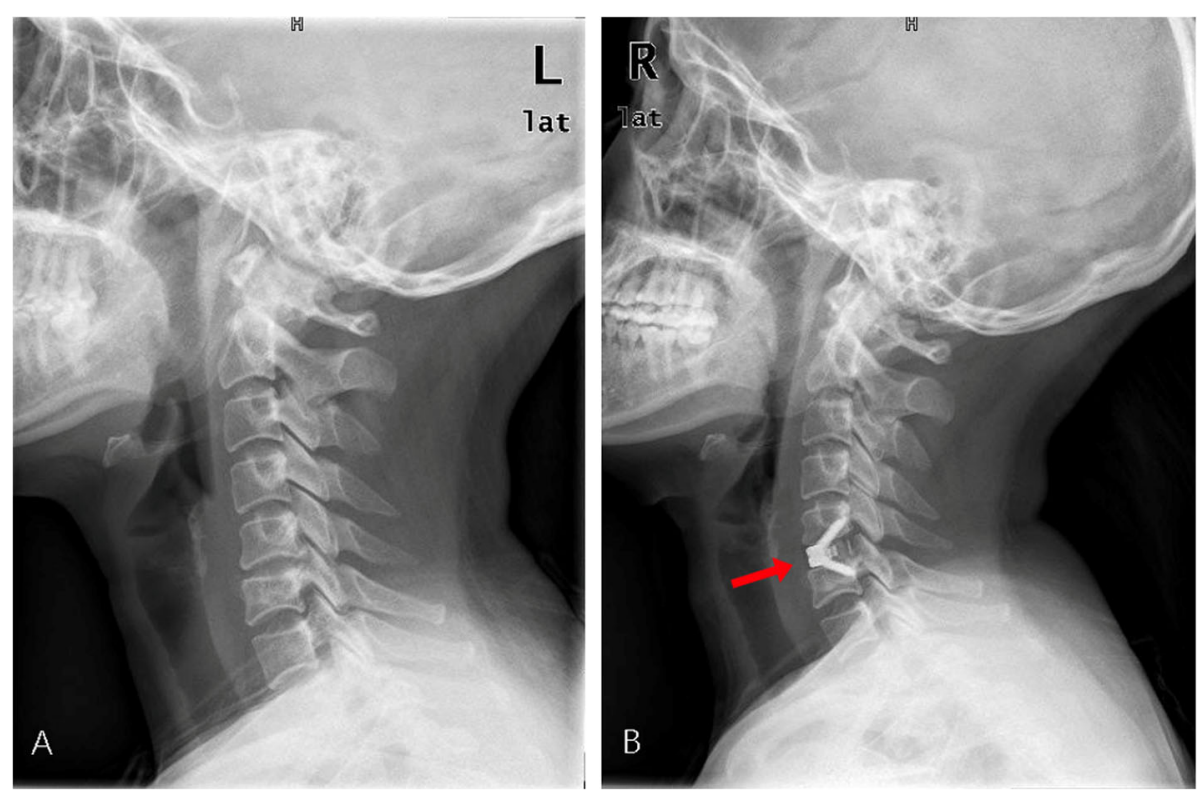

Fig. 3 The preoperative (a) and postoperative (b) lateral X-rays of a 40-year-old female patient who was diagnosed with cervical spondylotic myelopathy and underwent C5/6 ACDF with Zero-P. The $d \mathrm{O}-\mathrm{C}_{2} \mathrm{~A}$ was $8.62^{\circ}$. The Bazaz grading system showed mild postoperative dysphagia. The $X$-rays showed obvious $\mathrm{dC}_{2-7} \mathrm{~A}$ (red arrow)

profile plate design can minimize soft tissue irritation, thus decreasing the incidence of dysphagia after traditional ACDF. New devices for ACDF have been developed in recent years, such as the Zero-P Implant System. In theory, the Zero-P Implant System reduces the incidence of dysphagia after surgery due to the lack of posterior irritation and constriction by anterior plates.

Several retrospective studies have reported that the change in lordosis plays an important role in the development of dysphagia in both anterior and posterior

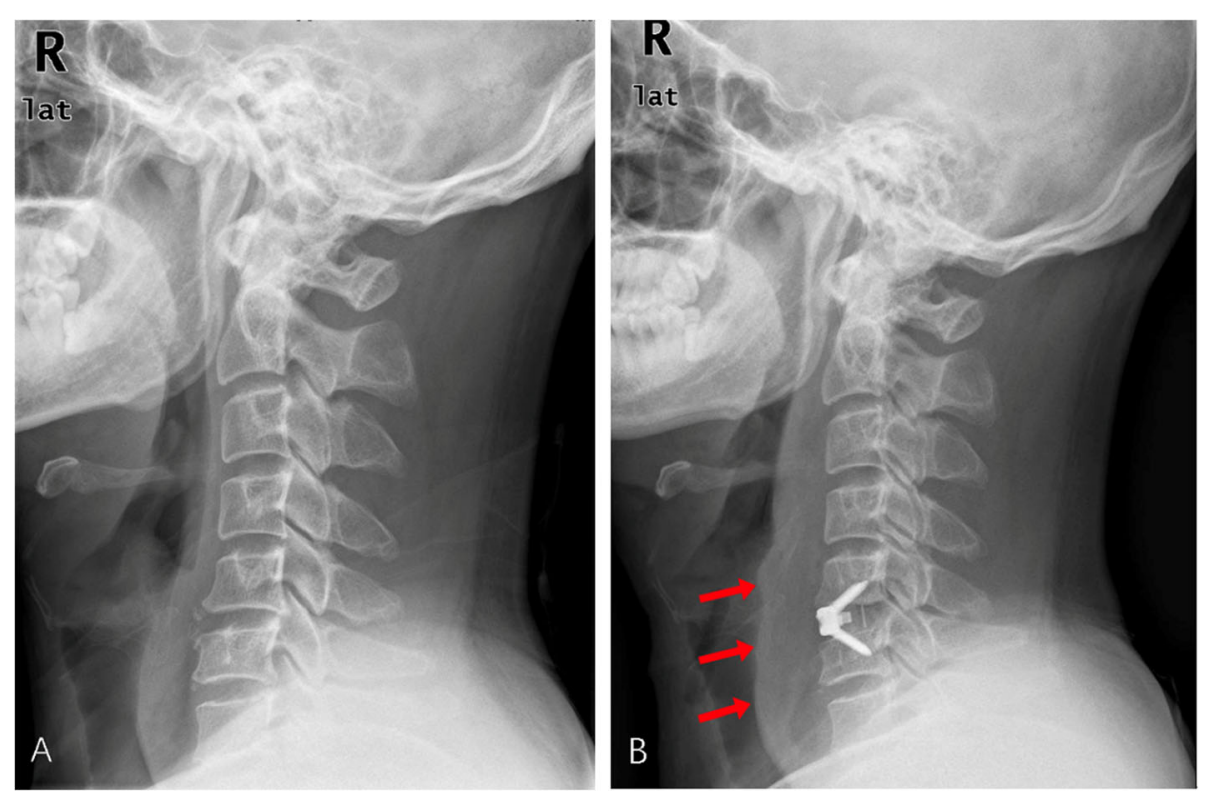

Fig. 4 The preoperative (a) and postoperative (b) lateral X-rays of a 37-year-old male patient who was diagnosed with cervical spondylotic myelopathy and underwent C5/6 ACDF with Zero-P. The PSTS was $6.3 \mathrm{~mm}$. The Bazaz grading system showed severe postoperative dysphagia. The X-rays showed obvious PSTS (red arrows). PSTS: Prevertebral soft-tissue swelling 
Table 4 The results of the logistic regression analysis between related factors and dysphagia ${ }^{a}$

\begin{tabular}{|c|c|c|c|c|c|}
\hline \multirow[t]{2}{*}{ Related factors } & \multirow[t]{2}{*}{ B } & \multirow[t]{2}{*}{$\mathbf{P}$} & \multirow[t]{2}{*}{ OR } & \multicolumn{2}{|l|}{$95 \% \mathrm{Cl}$} \\
\hline & & & & Lower bound & Upper bound \\
\hline Age & -0.008 & 0.776 & 0.992 & 0.939 & 1.048 \\
\hline BMl & 0.143 & 0.077 & 1.154 & 0.984 & 1.353 \\
\hline Smoking & 1.769 & 0.001 & 5.863 & 2.138 & 16.082 \\
\hline Estimated blood loss & -0.009 & 0.126 & 0.991 & 0.980 & 1.002 \\
\hline Prevertebral soft-tissue swelling & 1.788 & $<0.001$ & 5.975 & 2.891 & 12.350 \\
\hline $\mathrm{dC}_{2-7} \mathrm{~A}$ & 0.077 & 0.018 & 1.080 & 1.013 & 1.151 \\
\hline
\end{tabular}

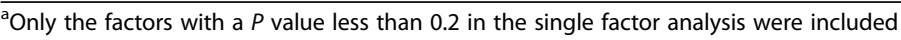

cervical spine surgery [11-13]. Tian et al. [13] found that $\mathrm{dC}_{2-7} \mathrm{~A}$ for dysphagia patients was significantly higher than for non-dysphagia patients after ACDF. In general, $\mathrm{dC}_{2-7} \mathrm{~A}$ could cause changes in the anatomical relationship between the cervical spine and the anterior esophagus, which may cause dysphagia. However, the traditional anterior cervical plate can better reconstruct the overall curvature of the cervical spine and the curvature of the surgical segment than the Zero-P [30, 31]. Studies focusing specifically on the effect of the $\mathrm{dC}_{2-7} \mathrm{~A}$ on the development of dysphagia after ACDF with the Zero-P are rare. Therefore, we designed this retrospective study.

In this study, the comparison of the $\mathrm{dC}_{2-7} \mathrm{~A}$ between the dysphagia group and the non-dysphagia group showed that the difference was significant. Meanwhile, the incidence of dysphagia when the $\mathrm{dC}_{2-7} \mathrm{~A}$ was $<-1^{\circ}$ was obviously less than when the $\mathrm{dC}_{2-7} \mathrm{~A}$ was $\geq-1^{\circ}$. A greater $\mathrm{dC}_{2-7} \mathrm{~A}$ was shown to be significantly associated with a higher incidence of dysphagia. Therefore, adjusting the $\mathrm{C}_{2-7}$ angle properly in ACDF with the Zero-P Implant System may reduce the incidence of dysphagia. Some surgeons exert more powerful traction on the prevertebral tissue and intervertebral space to restore the physiological curvature of the cervical spine, decrease postoperative cervical degeneration and create a larger space for the implant, and some insert the screws more smoothly during the operation; ignoring this may lead to an angle that is too large, resulting in the protrusion of the pharyngolaryngeal wall and, ultimately, postoperative dysphagia [32]. Notably, Spearman's correlation coefficient between the degree of dysphagia and $\mathrm{dC}_{2-7} \mathrm{~A}$ showed no significant correlation in the dysphagia group. We therefore can assume that the dysphagia is a type of subjective feeling, which might be different for similar anatomical changes after surgery.

We noticed that the risk factors for dysphagia after ACDF with Zero-P varied greatly in different studies. Miyata et al. [11] and Meng et al. [12]. reported that the difference between postoperative and preoperative $\mathrm{O}-\mathrm{C}_{2}$ is a key factor in the development of postoperative dysphagia after occipitocervical fusion. Kalb et al. reported that possible risk factors included multilevel surgeries, the involvement of $\mathrm{C}_{4-5}$ and $\mathrm{C}_{5-6}$, and age but not operating time in their study [33]. Jang et al. concluded that age and sex were not related to postoperative dysphagia [34]. Elderly age, female sex and multilevel surgery were found to be possible risk factors for postoperative dysphagia in the study by Zeng et al. [35]. Some factors, such as the change in O-C2 angle, sex, age, levels of surgery segments and the highest segment of surgery, were not associated with a higher incidence of dysphagia in this study. Several reasons for this are possible. First, the Zero-P Implant System can reduce the incidence of dysphagia after surgery compared with traditional ACDF because of the absence of an anterior cervical plate, possibly resulting in the lack of a significant difference between the two groups with the highest segments involved in the surgery and the levels of surgery. Second, the common application of the anterior cervical soft-tissue spreader reduces the intraoperative traction on the esophagus; injury to the recurrent laryngeal nerve (RLN) and superior laryngeal nerve (SLN) is also avoided due to the improvements in anterior cervical surgery in recent years. In addition, cultural factors in different regions may affect the risk factors for dysphagia. Notably, PSTS had an important effect on the occurrence of dysphagia in this study, consistent with previous findings $[36,37]$. This might be because the intra-operative traction of esophagus and trachea, split of prevertebral fascia, stimulation of implants or even the change in cervical physiological curvature can cause prevertebral softtissue swelling leading to dysphagia. Paying attention to minimizing the intra-operative traction and routine use of corticosteroids after surgery is necessary according to the result. Furthermore, smoking was significantly associated with a higher incidence of dysphagia in the ordinal logistic regression model in this study, and this has rarely been mentioned before. Possible reasons are that smoking can cause pharyngolaryngitis and increase the sensitivity of the pharynx and larynx. Studies with larger sample sizes are possibly needed to validate the authenticity of this result.

\section{Limitation}

The limitations of the study are as follows. First, adoption of the Bazaz scale is the primary limitation of this 
study. As an unvalidated grading scale used to evaluate dysphagia, this scale is based on qualitative information collected by an investigator to assess the patient's subjective sensation of difficulty when swallowing liquids and solids; this scale has been commonly applied in previous studies [16]. As the scale is based on subjective feelings, possible sensory disruptions causing postoperative dysphagia may be challenging to explain and may not reflect accurate clinical outcomes. The gold standard of dysphagia assessment, which is fiber optic endoscopic evaluation or video fluoroscopy, could be used to ensure the veracity of these findings $[38,39]$. Second, the limitations of the retrospective design are obvious; therefore, future randomized controlled studies are also needed to verify our conclusions. Third, not all potential risk factors, such as the changes in cervical curvature, were considered in the statistical analysis. In addition, the mechanisms by which the $\mathrm{dC}_{2-7} \mathrm{~A}$ affects the development of dysphagia after ACDF with the Zero-P Implant System are not completely clear. Therefore, multicenter and randomized controlled studies are needed to verify our conclusions in the future.

\section{Conclusion}

The difference between the postoperative and preoperative $\mathrm{C}_{2-7}$ angle has an important effect on the occurrence of dysphagia in patients undergoing Zero-P implant system interbody fusion surgery. Measurement and adjustment of the $\mathrm{C}_{2-7}$ angle during ACDF with Zero-P may be practical and essential in avoiding inadvertent postoperative dysphagia. Further randomized controlled studies are needed to validate these findings.

\begin{abstract}
Abbreviations
ACDF: Anterior cervical discectomy and fusion; Zero-P: Zero-profile standalone device; O-C2A: O-C2 angle; C2-7A: C2-7 angle; dC2-

7A: Difference between postoperative and preoperative C2-7 angle; dOC2A: Difference between postoperative and preoperative O-C2 angle; PSTT: Prevertebral soft tissue thickness; PSTS: Prevertebral soft-tissue swelling; BMI: Body mass index; OPLL: Ossification of the posterior longitudinal ligament; rhBMP-2: Recombinant human bone morphogenetic protein-2; AP: Anteroposterior; RLN: Recurrent laryngeal nerve; SLN: Superior laryngeal nerve
\end{abstract}

\section{Acknowledgements}

We acknowledge Ying Hong for contributing to the manuscript.

\begin{abstract}
Authors' contributions
$\mathrm{CH}$ was the lead investigator. $\mathrm{CH}, \mathrm{HL}$ and $\mathrm{BW}$ contributed to the conception of the study; $\mathrm{CH}, \mathrm{YM}$ and CD performed the experiment; $\mathrm{CH}, \mathrm{YY}$ and TW contributed significantly to analysis and manuscript preparation; $\mathrm{CH}$ and TW performed the data analyses and wrote the manuscript; $J Y$ and $\mathrm{HL}$ helped perform the analysis with constructive discussions. All author(s) read and approved the final manuscript.
\end{abstract}

\section{Funding}

This study was supported by: The Sichuan Province Science and Technology Program of China (grant no. 2019YFQ0002); the West China Hospital Research Project, Sichuan University (grant no. HX-H1812210); 1.3.5 project for disciplines of excellence-Clinical Research Incubation Project, West China Hospital, Sichuan University (grant no. 2019HXFH040); Key Research and Development Programs of Department of Science and Technology of Sichuan Province (grant no. 2020YFS0075).

\section{Availability of data and materials}

The datasets used and/or analysed during the current study are available from the corresponding author on reasonable request.

\section{Ethics approval and consent to participate}

The experimental protocol was established, according to the ethical guidelines of the Helsinki Declaration and was approved by the Medical Ethics Committee of West China Hospital, Sichuan University, China (No. 2019(416)). Written informed consent was obtained from individual or guardian participants.

\section{Consent for publication}

Written informed consent for publication was obtained from all participants.

\section{Competing interests}

The authors declare that they have no competing interests.

\section{Author details}

'Department of Orthopedic Surgery, West China Hospital, Sichuan University, No. 37 Guo Xue Xiang, Chengdu 610041, Sichuan, China. ${ }^{2}$ Department of Spinal Surgery, Beijing Jishuitan Hospital, The 4th Clinical Medical College of Peking University, No. 31, Xinjiekou East Street, Xicheng District, Beijing 100035, China.

Received: 11 July 2020 Accepted: 30 September 2020

Published online: 06 October 2020

\section{References}

1. Kaiser MG, Haid RW Jr, Subach BR, et al. Anterior cervical plating enhances arthrodesis after discectomy and fusion with cortical allograft. Neurosurgery. 2002;50(2):229-36.

2. Song K, Taghavi CE, Lee KB, et al. The efficacy of plate construct augmentation versus cage alone in anterior cervical fusion. Spine (Phila Pa 1976). 2009;34(26):2886-92.

3. Zdeblick TA, Cooke ME, Kunz DN, et al. Anterior cervical diskectomy and fusion using a porous hydroxyapatite bone graft substitute. Spine. 1994;19: 2348-57.

4. Anderson DG, Albert TJ. Bone grafting, implants, and plating options for anterior cervical fusions. Orthop Clin North Am. 2002;33:317-28.

5. Founlas KN, Kapsalaki EZ, Nikolakakos LG, et al. Anterior cervical discectomy and fusion associated complications. Spine (Phila Pa 1976). 2007;32(21): 2310-7.

6. Kasimatis GB, Panagiotopoulos E, Gliatis J, et al. Complications of anterior surgery in cervical spine trauma: an overview. Clin Neurol Neurosurg. 2009; 111(1):18-27.

7. Tortolani PJ, Cunningham BW, Vigna F, et al. A comparison of retraction pressure during anterior cervical plate surgery and cervical disc replacement: a cadaveric study. J Spinal Disord Tech. 2006;19(5):312-7.

8. Zhuang C, Zhou D, Tang X, et al. Clinicaloutcome of anterior cervical. discectomy andfusion using a zero-profile interbody fusion andfixation device for cervical spondylotic myeloath. Chin J of Repa and Reco Surg. 2015;29:751-5.

9. Hofstetter $C P$, Kesavabhotla K, Boockvar JA. Zero-profile anchored spacer reduces rateof dysphagia compared with ACDF with anteri-or plating. J Spinal Disord Tech. 2015;28E:284-90.

10. Yang $H$, Chen D, Wang $X$, et al. Zero-profile integrated plate and spacer device reduces rate of adjacent-level ossifi-cation development and dysphagia comparedto ACDF with plating and cage system. Arch Orthop Trauma Surg. 2015;135:781-7.

11. Miyata M, Neo M, Fujibayashi S, et al. O-C2 angle as a predictor of dyspnea and/or dysphagia after occipitocervical fusion. Spine (Phila Pa 1976). 2009; 34(2):184-8.

12. Meng $Y, W U T K$, Liu ZY, et al. The impact of the difference in O-C2 angle in the development of dysphagia after occipitocervical fusion: a simulation study in normal volunteers combined with a case-control study. Spine J. 2018;18:1388-97.

13. Tian $\mathrm{W}, \mathrm{Yu}$ J. The role of $\mathrm{C} 2-\mathrm{C} 7$ angle in the development of dysphagia after anterior and posterior cervical spine surgery. Dyspghagia. 2013;28:131-8.

14. Cheung KM, Mak KC, Luk KD. Anterior approach to cervical spine. Spine (Phila Pa 1976). 2012;37:E297-302. 
15. Cho W, Buchowski JM, Park Y, et al. Surgical approach to the cervicothoracic junction: can a standard SmithRobinson approach be utilized. J Spinal Disord Tech. 2012;25:264-7.

16. Bazaz R, Lee MJ, Yoo JU. Incidence of dysphagia after anterior cervical spine surgery: a prospective study. Spine (Phila Pa 1976). 2002;27:2453-8.

17. Mummaneni PV, Burkus JK, Haid RW, et al. Clinical and radiographic analysis of cervical disc arthroplasty compared with allograft fusion:a randomized controlled clinical trial. J Neurosurg Spine. 2007;6(3):198-209.

18. Ohara A, Miyamoto K, Naganawa T, et al. Reliabilities of and correlations among five standard methods of assessing the sagittal alignment of the cervical spine. Spine (Phila Pa 1976). 2006;31(22):2585-91 discussion 2592.

19. Ota M, Neo M, Aoyama T, et al. Impact of the O-C2 angle on the oropharyngeal space in normal patients. Spine (Phila Pa 1976). 2011;36(11):E720-6.

20. Lee SH, Kim KT, Suk KS, et al. Effect of retropharyngeal steroid on prevertebral soft tissue swelling following anterior cervical discectomy and fusion: a prospective, randomized study. Spine (Phila Pa 1976). 2011;36(26):2286-92.

21. Fountas KN, Kapsalaki EZ, Nikolakakos LG, et al. Anterior cervical discectomy and fusion associated complications. Spine. 2007;32:2310-7.

22. Papadopoulou S, Exarchakos G, Beris A, et al. Dysphagia associated with cervical spine and postural disorders. Dysphagia. 2013;28:469-80.

23. Starmer HM, Riley LH 3rd, Hillel AT, et al. Dysphagia, short-term outcomes, and cost of care after anterior cervical disc surgery. Dysphagia. 2014;29:68-77.

24. Rihn JA, Kane J, Albert $\mathrm{TJ}$, et al. What is the incidence and severity of dysphagia after anterior cenvical surgery. Clin Orthop Relat Res. 2011;469(3):658-65.

25. Yue WM, Brodner W, Highland TR. Persistent swallowing and voice problems after anterior cervical discectomy and fusion with allograft and plating: a 5 to 11-year follow-up study. Eur Spine J. 2005;14(7):677-82.

26. Clave P, Shaker R. Dysphagia: current reality and scope of the problem. Nat Rev Gastroenterol Hepatol. 2015;12:259-70.

27. Skeppholm M, Olerud C. Comparison of dysphagia between cervical artificial disc replacement and fusion: data from a randomized controlled study with two years of follow up. Spine (Phila Pa 1976). 2013;38:E1507-10.

28. Kepler CK, Rihn JA, Bennett JD, et al. Dysphagia and soft-tissue swelling after anterior cervical surgery: a radiographic analysis. Spine J. 2012;12:639-44.

29. Lee MJ, Bazaz R, Furey CG, et al. Influence of anterior cervical plate design on dysphagia: a 2-year prospective longitudinal follow-up study. J Spinal Disord Tech. 2005;18(5):406-9.

30. Chen YY, Liu Y, Chen HJ, et al. Comparison of curvature between the zero-P spacer and traditional cage and plate after 3-level anterior cervical discectomy and fusion. Clinical Spine Surgery. 2017;30(8):E1111-6.

31. Vanek P, Bradac O, Delacy P, et al. Anterior interbody fusion of the cervical spine with zero-P spacer: prospective comparative study-clinical and radiological results at a minimum 2 years after surgery. Spine (Phila Pa 1976). 2013:38(13):E792-7.

32. Joaquim AF, Murar J, Savage JW, et al. Dysphagia after anterior cervical spine surgery: a systematic review of potential preventative measures. Spine J. 2014;14:2246-60

33. Kalb S, Reis MT, Cowperthwaite MC, et al. Dysphagia after anterior cervical spine surgery: incidence and risk factors. World Neurosurg. 2012;77:183-7.

34. Jang JW, Park JH, Rhim SC. Does plate profile affect postoperative dysphagia following anterior cervical spine surgery? I Clin Neurosurg. 2014; 21:78-81.

35. Zeng JH, Zhong ZM, Chen JT. Early dysphagia complicating anterior cervical spine surgery: incidence and risk factors. Arch Orthop Trauma Surg. 2013; 133:1067-71.

36. Smucker JD, Rhee JM, Singh K, et al. Increased swelling complications associated with off-label usage of rhBMP-2 in the anterior cervical spine. Spine (Phila Pa 1976). 2006;31(24):2813-9.

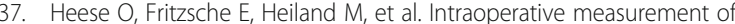
pharynx/esophagus retraction during anterior cervical surgery Part II: perfusion. Eur Spine J. 2006;15(12):1839-43.

38. Arens C, Deitmer T, Schoenweiler R. Fiber optic endoscopic evaluation of swallowing on the stroke unit. Nervenarzt. 2014;85:481-2.

39. Badenduck LA, Matthews TW, McDonough A, et al. Fiber-optic endoscopic evaluation of swallowing to assess swallowing outcomes as a function of head position in a normal population. J Otolaryngol Head Neck Surg. 2014; 43(1):9.

\section{Publisher's Note}

Springer Nature remains neutral with regard to jurisdictional claims in published maps and institutional affiliations.

\section{Ready to submit your research? Choose BMC and benefit from:}

- fast, convenient online submission

- thorough peer review by experienced researchers in your field

- rapid publication on acceptance

- support for research data, including large and complex data types

- gold Open Access which fosters wider collaboration and increased citations

- maximum visibility for your research: over $100 \mathrm{M}$ website views per year

At $\mathrm{BMC}$, research is always in progress.

Learn more biomedcentral.com/submissions 